colitis, and anorectal conditions such as dyschezia and spasm, whether idiopathic or secondary to local disease (fissure, ulcer, hemorrhoids). Any such obstruction to the fecal column, particularly when the effect is intermittent or recurrent, tends to throw back the contents to the head of the colon (exaggerated antiperistalsis), and thus brings on the usual sequence of bypertrophy and dilatation, with local irritation and subjective discomfort.

It is much to be desired that a wider recognition of this really comnion syndrome will lead to correct diagnosis and appropriate treatment, and so prevent not only the possible terminal stage of "perforating ulcers of the cecum," but also the injudicious and unhelpful removal of innumerable "chronically diseased appendixes" that do not exist in reality. John L. Kantor, M.D., New York.

\section{THE CASE OF WILLETTA HUGGINS}

To the Editor:-I have no quarrel with Professor Jastrow, as I am neither a psychologist nor an oculist; but I presided at the meeting of the Chicago Medical Society when the case of Willetta Huggins was presented, and I believe that, in justice to the intelligence of the audience, those who read his article in The Journal of June 17 should know how the sight test was applied before the Chicago Medical Society.

A pair of ordinary dust goggles was used, and over each giass was placed a piece of dark paper, and then a heavy pad of cotton. I placed these over my own eyes first, and then over the eyes of Miss Huggins.

If this young lady read with a slit of vision as Professor Jastrow states when she performed the tests before our members, it is even more marvelous than his theory of the "will to believe."

President, Chicago Medical Society.

J. S. Nagei. M.D. Chicago.

\section{MEDICAL TERMINOLOGY IN GERMANY}

To the Editor:-Peculiar results of the European war continue to crop up in unexpected-or at least unforeseenplaces, from time to time. This is true not only in politics, geography and finance, but in art and science as well. In 1920, the Vereinigung der deutschen medizinischen Fachpresse designated a commission to collaborate with the Deutsche Gesellschaft für innere Medizin in selecting German terms which might replace French and English expressions that have been so long in use in medical literature as to have become in many instances a part of the medical language of all nations. The Deutsche medizinische Wochenschrift (48:493, 1922), the Mïnchener medizinische Wochenschrift $(69: 454,1922)$ and other medical periodicals from Germany report the results of this collaboration and give the list of the French and English phrases to be interdicted and their German equivalents. Of these new terms, many successfully convey their exact meaning at a glance; others require a little thoughtful investigation, while still others are composed etymologically of elements so nontechnical that their medical meaning is not easily arrived at-unless, perhaps, by a person "born in (the) two languages"-French and German, or English and German. Taking into account German unity and the German habit of discipline, we may assure ourselves that this terminology will secure instantaneous and universal adoption at the hands of writers on professional themes in Germany, and that such old friends as "contrecoup" and "tic douloureux" will disappear henceforth from German medical literature. It thus becomes important that those who avail themselves of the German periodicals-and especially those engaged in bibliography and the work of classification-- should have at hand the list (which is appended) of the new German expressions and their older French and English equivalents.

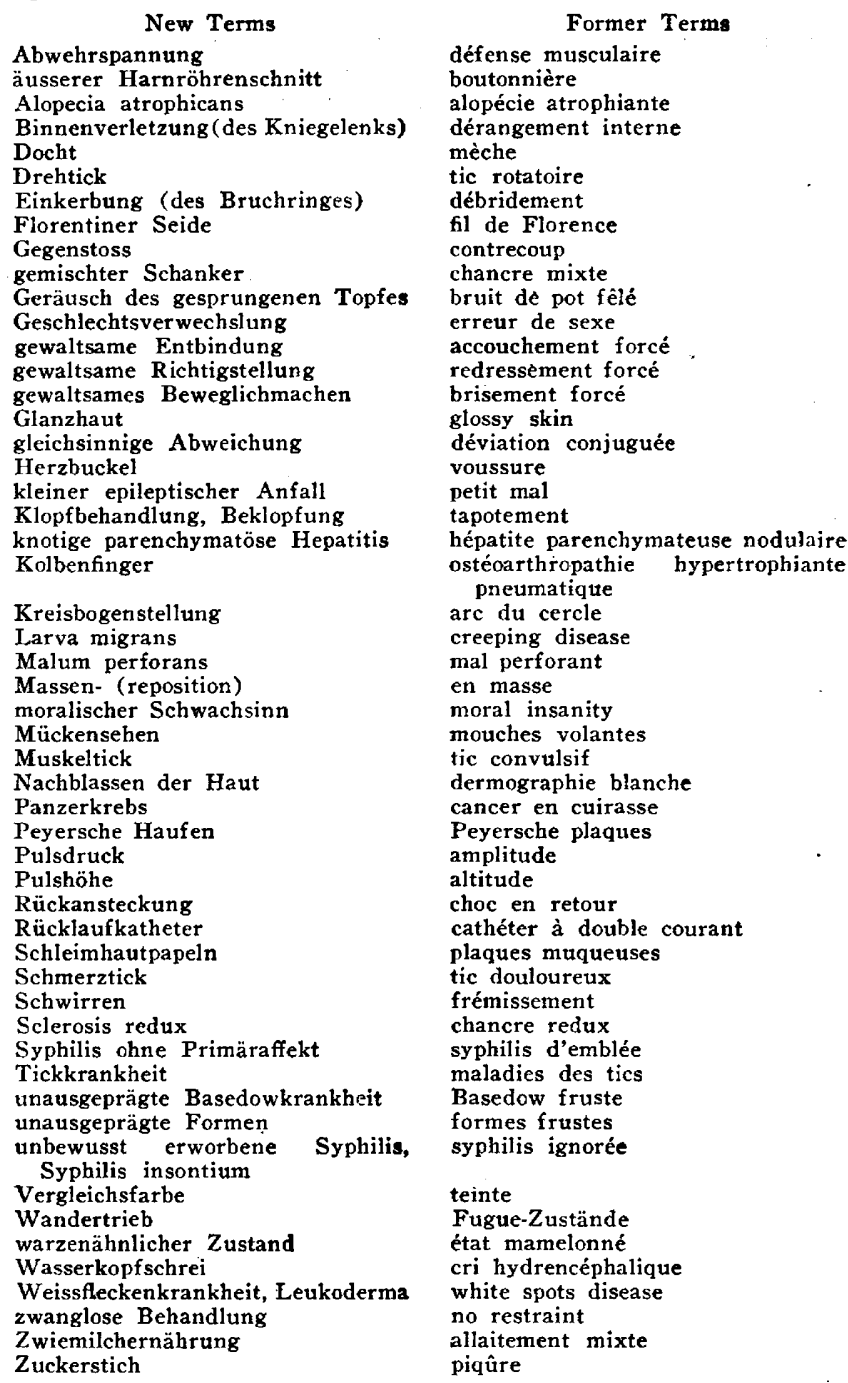

A. N. Tasker, M.D., Washini: ion, D. C.

Major, Medical Corps, U. S. Army; Associate Editor, Index Medicus.

[Comment.-It remains to be seen whether language can be created by edict in the new Germany.-ED.]

\section{"MEDICAL EDUCATION"}

To the Editor:-I have just read (The Journal, June 3, p. 1743) certain reflections of a student relative to medical education. Now for some suggestions anent that topic from the practitioner's standpoint.

In my humble opinion (M.D., Columbia, 1904) too much study is required of a purely theoretical nature. The subjects of physiologic chemistry, materia medica, comparative anatomy, etc., while extremely interesting, have too many hours of the course devoted to them. Would it not be wiser to focus on twenty drugs and have a broad, indelible knowledge of these, rather than ramble along over all the pharmacopeia? One should learn twenty drugs thoroughly and well, and read up the other 999 as parallel.

What does the young graduate know of such topics as distribution of physicians in the United States; office equipment -how many rooms, where best to locate in a city or town, a roentgen-ray room, laboratory; bill collecting, how to go about it; how to collect difficult bills; office nurse; relation- 